\title{
Моделювання робочих параметрів модернізованих тепловозів як об'сктів випробувань
}

В статті розроблені моделі визначення основних параметрів модернізованих тепловозів для їх використання під час приймальних випробувань. Результати моделювання можуть бути використані при визначенні показників модернізованих тепловозів, щзо дозволить скоротити обсяги проведення натурних приймальних випробувань і зменшити їх вартість.

Ключові слова: тепловоз, об’єкт випробувань, модернізація, моделювання

\begin{abstract}
Постановка проблеми
В теперішній час тяговий рухомий склад (ТРС) українських залізниць вичерпав свій ресурс більш ніж на $90 \%$. Особливо це стосується тепловозів, які знаходяться в експлуатації більше 30 років (тепловоз M62). Комплексною програмою передбачена можливість як закупівлі нового, так і модернізації існуючого рухомого складу, за умови наявності резервів міцності несучої конструкції. Другий варіант може виступати більш доцільним, особливо в умовах необхідності зменшення економічних витрат.

При цьому виникає практична необхідність у проведенні приймальних випробувань модернізованих тепловозів [1]. Аналіз наукових праць показав [2 - 7] необхідність наукового обгрунтування вибору видів приймальних випробувань модернізованих тепловозів. Враховуючи існуючі напрацювання в теоретичному i практичному дослідження тепловозів, постає можливість використання математично-розрахункових моделей для визначення основних показників та характеристик модернізованих тепловозів, які перевіряються під час приймальних випробувань.
\end{abstract}

Мета статті - розробити математичну модель визначення робочих параметрів функціонування модернізованого тепловоза як об'єкта випробувань для оптимізації обсягів приймальних випробувань.

\begin{tabular}{l}
\hline Основний матеріал \\
\hline \multicolumn{4}{c}{ Розроблювана модель повинна описувати роботу } \\
основних вузлів тепловоза, від яких залежить \\
показники функціонування, вимоги до яких вказані в \\
технічному завданні на тепловоз та в інших \\
нормативних документах. В результаті використання \\
моделі повинні бути отримані значення робочих \\
параметрів, по яким можливо отримати
\end{tabular}

() А.П. Фалендиш, Д.А. Іванченко, 2016 характеристики механічного руху, електричних, теплових, пневматичних процесів, а саме: потужності, сили тяги, швидкості, напруги, сили струму, температури, тиску та інш. Ці характеристики далі порівнюються 3 запроектованими i заявленими відповідно до документації виробника. Завданням роботи $є$ підтвердження адекватності моделі та формування висновків щодо модернізованого тепловозу як об' єкта випробувань.

Склад моделі відображає конструкцію та принципи роботи тепловоза і містить наступні частини:

- модель силової установки (двигуна внутрішнього згорання) тепловоза;

- модель тягової електричної передачі;

- модель руху поїзда 3 врахуванням умов експлуатації.

До моделі силової установки включений тепловий розрахунок двотактного дизеля. Параметри робочого тіла визначаються наступними параметрами:

$$
\left\{\begin{array}{l}
L_{0}, l_{0}=f(C, H, O) \\
M_{1}=f\left(\alpha, L_{0}\right) \\
M_{2}=f\left(M_{C O 2}, M_{H 2 O}, M_{O 2}, M_{N 2}\right)
\end{array},\right.
$$

де $L_{0}, l_{0}$ - теоретично необхідна кількість повітря;

$C, H, O$ - елементарний склад палива;

$M_{1}, M_{2}$ - кількість свіжого заряду і загальна кількість продуктів згорання;

$M_{\mathrm{CO} 2}, M_{\mathrm{H} 2 \mathrm{O}}, M_{\mathrm{O} 2}, M_{\mathrm{N} 2}$ - кількість компонентів продуктів згорання.

Параметри навколишнього середовища і залишкові гази:

$$
\left\{\begin{array}{l}
T_{k}=f\left(T_{0}, p_{k}, p_{0}, n_{k}\right) \\
T_{r}, p_{r}
\end{array},\right.
$$


де $T_{k}$ - температура навколишнього середовища;

$T_{0}, p_{0}$ - атмосферні умови;

$T_{r}, p_{r}$ - температура і тиск остаточних газів.

Параметри процесу впуску:

$$
\left\{\begin{array}{l}
p_{a}=f\left(p_{k}, \Delta p_{a}\right) \\
\gamma_{r}=f\left(T_{k}, T_{r}, p_{r}, \varepsilon, p_{a}, p_{r}\right), \\
T_{a}=f\left(T_{k}, \gamma_{r}, T_{r}\right) \\
\eta_{v}=f\left(T_{k}, \varepsilon, p_{a}, p_{r}, p_{k}\right)
\end{array}\right.
$$

де $T_{a}, p_{a}$ - температура і тиск в кінці впуску;

$\Delta p_{a}$ - втрати тиску на впуску;

$\gamma_{r}$ - коефіцієнт залишкових газів;

$\eta_{v}$ - коефіцієнт наповнення.

Параметри процесу стиснення:

$\left\{\begin{array}{l}p_{c}=f\left(p_{a}, \varepsilon, n_{1}\right) \\ T_{c}=f\left(T_{a}, \varepsilon, n_{1}\right)\end{array}\right.$, де $T_{c}, p_{c}$ - тиск і температура вкінці стиснення;

$n_{1}$ - середній показник адіабати і політропи стиснення;

Параметри процесу згорання:

$$
\left\{\begin{array}{l}
\mu_{0}=f\left(M_{1}, M_{2}\right) \\
\mu=f\left(\mu_{0}, \gamma_{r}\right) \\
H_{r s m}=f\left(H_{u}, M_{1}, \gamma_{r}\right) \\
T_{z}, p_{z}=f\left(\lambda, p_{c}\right) \\
\rho=f\left(\mu, T_{z}, \lambda, T_{c}\right)
\end{array}\right.
$$

де $\mu_{0}, \mu$ - коефіцієнти молекулярної зміни свіжої і робочої суміші;

$H_{r s m}, H_{u}$ - теплота згорання робочої суміші і нижня теплота згорання палива;

$T_{z}$ - температура в кінці видимого процесу згорання, що визначається з рівняння

$\left[\phi_{z} \cdot H_{r s m}+\left[\left(m c_{V^{\prime}}\right)+8,315 \cdot \lambda\right] \cdot t_{C}+2270 \cdot(\lambda-\mu)\right]-\mu \cdot\left(t z m c_{P^{\prime \prime}}\right) \cdot t_{z}=0$,

де $\phi_{z}$ - коефіцієнт використання теплоти;

$\lambda$ - ступінь підвищення тиску в дизелі;

$\left(m c_{V^{\prime}}\right),\left(t z m c_{P^{\prime \prime}}\right)$ - середня мольна теплоємність продуктів згорання в дизелі;

$T_{z}=t_{z}+273$;

$\rho$ - ступінь попереднього розширення.

Параметри процесу розширення:

$\left\{\begin{array}{l}\delta=f(\varepsilon, \rho) \\ p_{b}=f\left(p_{z}, \delta, n_{2}\right) \\ T_{b}=f\left(T_{z}, \delta, n_{2}\right)\end{array}\right.$,

де $T_{b}, p_{b}$ - температура і тиск в кінці розширення;

$\delta$ - ступінь розширення.

Індикаторні параметри робочого циклу:

$$
\left\{\begin{array}{l}
p_{i^{\prime}}=f\left(p_{c}, \varepsilon, \lambda, \rho, n_{2}, \delta, n_{1}\right) \\
p_{i}=f\left(\phi_{h}, p_{i^{\prime}}\right) \\
\eta_{i}=f\left(p_{i}, l_{0}, \alpha, H_{u}, p_{k}, \eta_{V}\right. \\
g_{i}=f\left(H_{u}, \eta_{i}\right)
\end{array},\right.
$$

де $p_{i^{\prime}}$ - теоретично середній індикаторний тиск; $p_{i}$ - середній індикаторний тиск;

$\phi_{h}$ - коефіцієнт повноти діаграми;

$g_{i}$ - індикаторна питома витрата палива.

Ефективні параметри роботи дизеля:

$$
\left\{\begin{array}{l}
p_{e}=f\left(p_{i}, p_{m}\right) \\
p_{m}=f\left(V_{\tilde{n} \partial}\right) \\
g_{e}=f\left(p_{e}, p_{i}, H_{u}, \eta_{e}\right.
\end{array},\right.
$$

де $p_{e}, p_{m}$ - середньо ефективний тиск і тиск механічних втрат;

$g_{e}$ - ефективна питома витрата палива.

Результати моделювання силової установки використовуються при моделюванні робочих параметрів функціонування передачі потужності.

Модель тягової електричної передачі побудована на залежностях основних параметрів їі функціонування та законах збереження енергії при передачі потужності від дизеля до колісних пар тепловоза.

Основні параметри тягової передачі розраховуються по наступним залежностям: 


$$
\left\{\begin{array}{l}
\omega_{o}=\frac{V_{T} \mu_{s n}}{3,6 R_{k}}, \sum M_{o}=\frac{F_{T} R_{k}}{\eta_{s n} \mu_{s n}}, M_{o}=\frac{\sum M_{o}}{6}, \\
P_{t}=\frac{M_{o} \omega_{o}}{1000}, I_{o}=\frac{I_{\Gamma}}{6}, \Phi_{o}=\frac{M_{o}}{0,98 C_{o} I_{o}}, \\
E_{o}=C_{o} \Phi_{o} \omega_{o}, U_{o}=E_{o}+I_{o} R_{o}, P_{\Gamma}=\frac{6 U_{o} I_{o}}{1000}, \\
E_{\Gamma}=U_{\Gamma}+I_{\Gamma} R_{\Gamma}, \Phi_{\Gamma}=\frac{E_{\Gamma}}{C_{\Gamma} \omega}, M_{e l \Gamma}=C_{\Gamma} \Phi_{\Gamma} I_{\Gamma}, \\
\eta_{\Gamma}=\frac{0,96 U_{\Gamma}}{E_{\Gamma}}, P_{D}=\frac{P_{\Gamma}}{\eta_{\Gamma}}, M_{D}=\frac{1000 P_{D}}{\omega}, \\
G_{f}=M_{e} \omega g_{e} 10^{-6}, g_{c}=\frac{1000 \pi G_{f}}{30^{2} \omega}
\end{array}\right.
$$

В результаті моделювання отримані основні характеристики тепловозів:

залежність потужності дизеля від циклової подачі палива та від кутової швидкості колінчатого валу дизеля - на рис. 1;

залежність потужності і крутного моменту від частоти обертання вала дизеля - на рис. 2;

залежність потужності від кутової швидкості колінчатого вала дизеля - на рис. 3;

залежність ККД тепловоза від кутової швидкості колінчатого вала дизеля - на рис. 4.

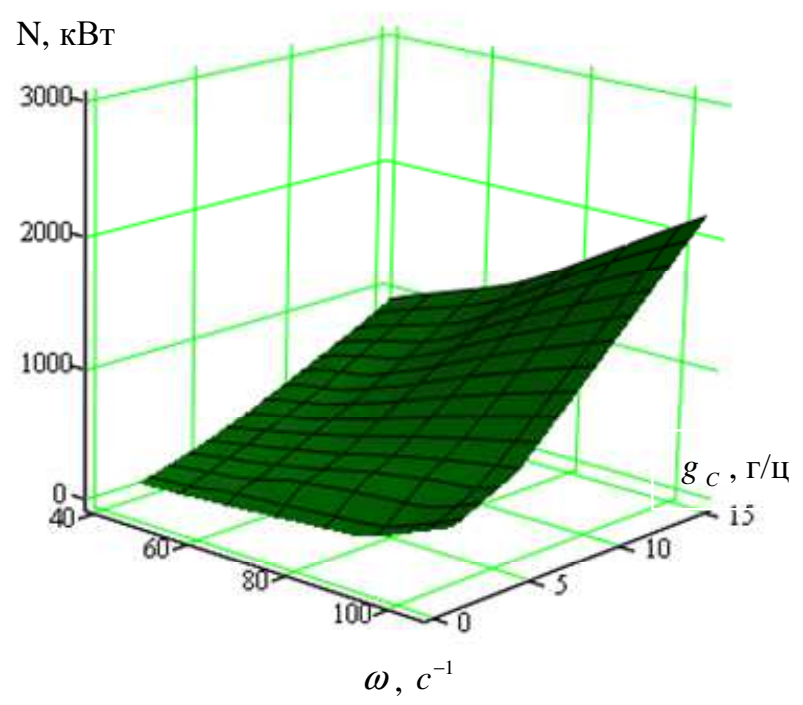

Рис. 1. Залежність потужності дизеля від циклової подачі палива та від кутової швидкості колінчатого валу дизеля

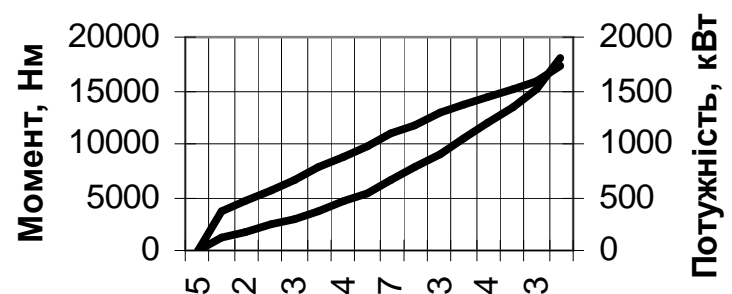

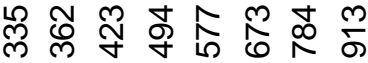

Частота, об/хв

Рис. 2. Залежність потужності і крутного моменту від частоти обертання вала дизеля

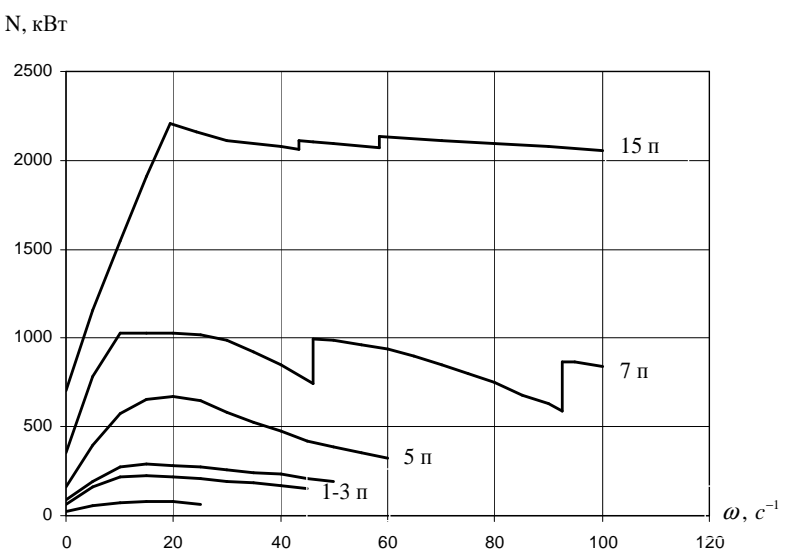

Рис. 3. Потужність по позиціям контролера машиніста

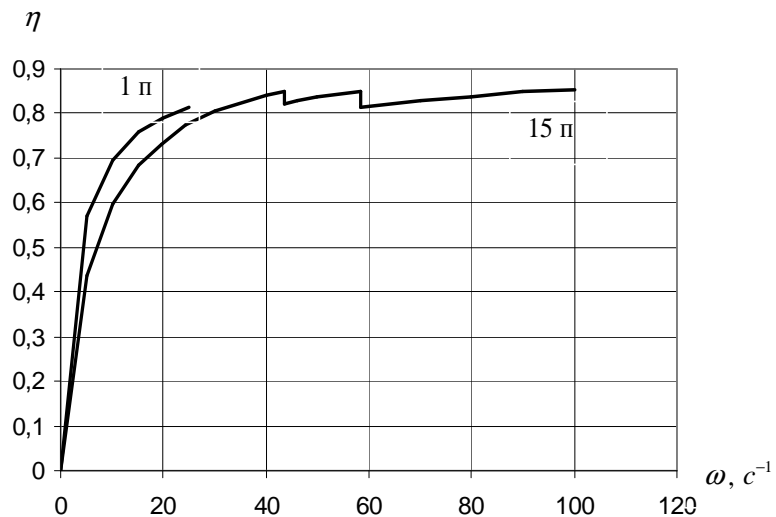

Рис. 4. Залежність ККД тепловоза від кутової швидкості колінчатого вала дизеля

Динамічна модель розрахунку параметрів руху поїзда формується на основі диференціальних рівнянь, що описують залежність параметрів робочих процесів дизеля, отриманих при їх моделюванні, і параметрів руху поїзда 3 урахуванням моделювання параметрів передачі потужності. Рівняння динамічної моделі: 


$$
\left\{\begin{array}{l}
J \cdot \chi^{\prime}(t)-a \cdot \chi(t) \cdot m(t)-b \cdot m(t)+C_{g} \cdot k_{\Phi} \cdot \chi(t) \cdot \frac{6 \cdot C_{g} \cdot k_{\Phi} \cdot \chi(t) \cdot\left(\frac{\pi}{30}\right) \cdot \chi(t)}{C_{t} \cdot k \cdot \omega(t)+\left(R_{a}+6 \cdot R_{G}\right)}=0 \\
J_{p} \cdot \omega^{\prime}(t)-0,9 \cdot 6 \cdot C_{t} \cdot k \cdot\left[\frac{C_{g} \cdot k_{\Phi} \cdot \chi(t) \cdot\left(\frac{\pi}{30}\right) \cdot \chi(t)}{C_{t} \cdot k \cdot \omega(t)+\left(R_{a}+6 \cdot R_{g}\right)}\right]^{2}+ \\
{\left[\begin{array}{l}
{\left[\left(1,9+0,008 \cdot 0,427 \cdot \omega(t)+0,00025 \cdot(\omega(t) \cdot 0,427)^{2}\right] \cdot m_{l} \cdot 9,81+\right]} \\
{\left[\begin{array}{l}
\left.0,7+\frac{3+0,09 \cdot \omega(t) \cdot 0,427+0,002 \cdot(\omega(t) \cdot 0,427)^{2}}{q}\right] \cdot m_{s} \cdot 9,81
\end{array}\right] \cdot k_{f c}=0}
\end{array}\right.}
\end{array}\right.
$$

При використанні розглянутих моделей необхідно використовувати тягові характеристики модернізованих і штатних тепловозів. Тому проведено апроксимацію тягових характеристик тепловозу М62 і модернізованого тепловозу М62М. Результати апроксимації приведено на рис. 5, 6.

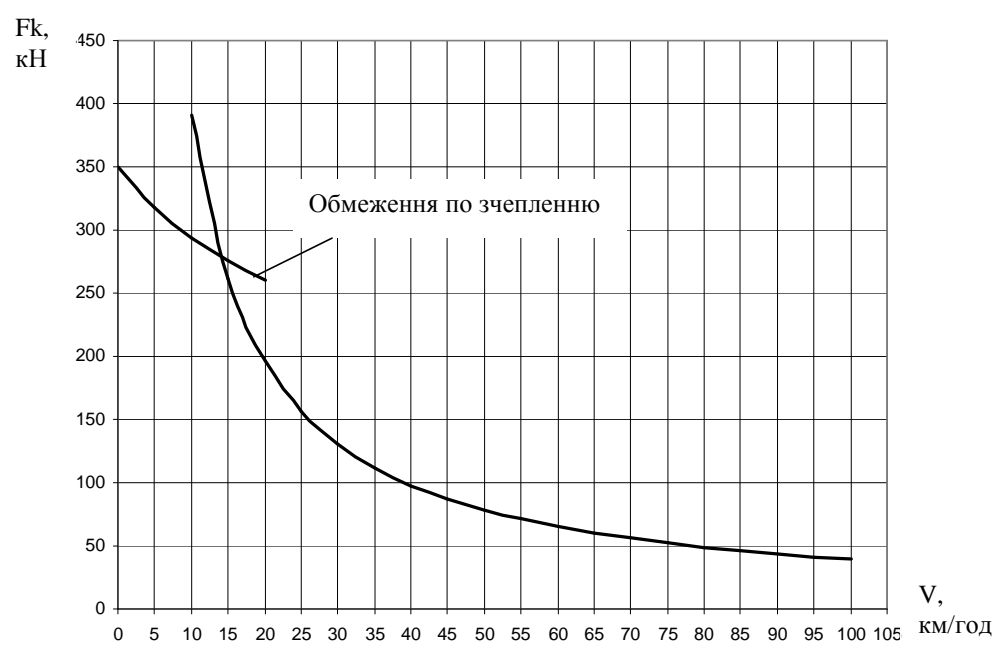

Рис. 5. Тягова характеристика тепловоза M62

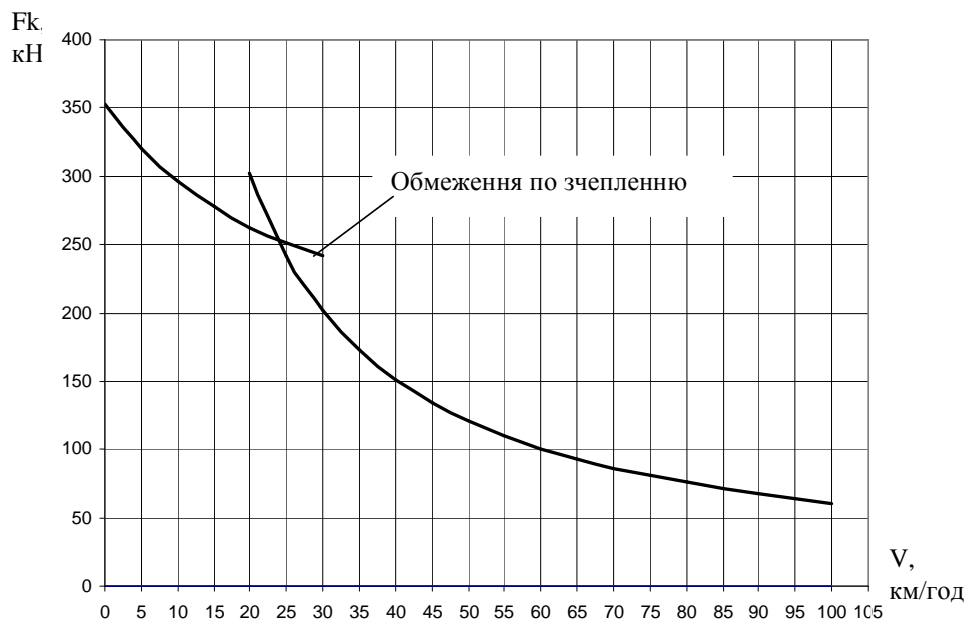

Рис. 6. Тягова характеристика модернізованого тепловозу М62М 
Результати апроксимації тягових характеристик представлені у формулах (12 - 13):

$$
\left\{\begin{array}{l}
0 \leq V \leq 11,5 \mathrm{kM} / \text { aод; } f(V)=165,76 \cdot V^{2}-7370,7 \cdot V+350226 \\
11,5<V<35 \mathrm{kM} / \text { əoд; } f(V)=-2,7872 \cdot V^{3}+415,14 \cdot V^{2}-21636 \cdot V+486225 \\
35 \leq V \leq 60 \mathrm{kM} / \text { əoд; } f(V)=0,0654 \cdot V^{3}+24,525 \cdot V^{2}-4666,3 \cdot V+248193 \\
60<V \leq 100 \mathrm{kM} / \text { əoд; } f(V)=0,0818 \cdot V^{3}-13,314 \cdot V^{2}-281,45 \cdot V+117776 ;
\end{array}\right.
$$

$$
\left\{\begin{array}{l}
0 \leq \mathrm{V} \leq 24 \mathrm{kM} / \text { eod; } \mathrm{f}(\mathrm{V})=0,118+5 /(27,5+\mathrm{V})) \cdot 120000 \cdot 9,81 \\
24<\mathrm{V} \leq 100 \mathrm{kM} / \text { əod; } \mathrm{f}(\mathrm{V})=3,6 \cdot 2238 \cdot 0,75 \cdot 1000 / \mathrm{V}
\end{array}\right.
$$

\begin{abstract}
Висновки
Розроблені моделі визначення основних параметрів модернізованих тепловозів дозволяють використовувати їх при проведенні приймальних випробувань 3 метою зменшення обсягів натурних експериментів (випробувань). Урахування оптимального вибору видів приймальних випробувань дозволить скоротити витрати на їх проведення при забезпеченні достовірності визначення показників модернізованих тепловозів.
\end{abstract}

\section{Література}

1. Правила технічної експлуатації залізниць України: Затверджено наказом Міністерства транспорту України від 20 грудня 1996 р. №411// Офіційний вісник України.-1997.

2. Методичні вказівки 3 підготовки і проведення приймальних випробувань тягового рухомого складу та його складових [Текст]. - Київ, 2005. $80 \mathrm{C}$.

3. Фалендыш, А. П. Анализ работ по проведению и выбору объемов испытаний тягового подвижного состава [Текст] / А. П. Фалендыш, С. Г. Жалкин, Д. А. Иванченко // Зб. наук. праць УкрДАЗТ. 2009. - №. 108. - С. 24-30.

4. Матяш, В. О. Метод визначення обсягів випробувань тягового рухомого складу на основі бази технічних рішень [Текст] / В. О. Матяш, Д.А. Иванченко // Вісник Східноукраїнського національного університету імені Володимира Даля. - 2014. -№3. - С. 86-89.

5. Иванченко, Д. А. Методы и модели выбора объема испытаний модернизированного тягового подвижного состава [Текст] / Д. А. Иванченко // Вісник Східноукраїнського національного університету імені Володимира Даля. - 2015. № 1. - C. 257-261.

6. Tartakovskyi, E. Refining the models of performing service tests of upgraded locomotives / Eduard Tartakovskyi, Anatoliy Falendysh, Artem Zinkivskyi, Sergey Mikheev // Eastern-European Journal of Enterprise Technologies. - 2015. - Vol. 2, N 3(74). -
P. 26-31. - Way of Access : DOI : 10.15587/17294061.2015.39849.

7. Falendysh, A. Research of improved mathematical models at operational tests of diesel locomotives [Text] / Anatoliy Falendysh, Artem Zinkivskyi, Nikita Bragin: // TEKA. COMMISSION OF MOTORIZATION AND ENERGETICS IN AGRICULTURE - 2014, Vol. 14, No.1, 18-27.

Фалендыш
рабочих
параметров тепловозов как объектов испытаний. В статье разработаны модели определения основных параметров модернизированных тепловозов для их использования во время приемочных испытаний. Результаты моделирования могут быть использованы при определении показателей модернизированных тепловозов, что позволит сократить объемы проведения натурных приемочных испытаний и уменьшить их стоимость.

Ключевые слова: тепловоз, объект испытаний, модернизация, моделирование.

Falendysh A., Ivanchenko D. Modeling of the operating parameters of modernized locomotives as test objects. Models to determine main parameters of modernized diesel locomotives for their use during qualification tests have been developed in the article.

The model structure corresponds to the main power equipment of diesel locomotives with electrical power transfer. Working procedures of a diesel engine have been considered and effective indices of its work have been determined.

The characteristics of power and a torque depending upon angular velocity of a diesel engine crankshaft rotation as well as dependencies of power and efficiency on operating mode of a power plant are of special interest. The obtained dynamic model of train movement parameter calculation is based on the use of differential equations connecting mechanical motion characteristics of a diesel engine and wheel pairs of a diesel engine. 
The model used the tractive characteristic of a modernized diesel locomotive M62M approximated by the method of the smallest quadrates. The results of modelling can be used while determining indices of modernized diesel locomotives which will allow reducing the volumes of qualification tests on location and cutting down their cost.

Key words: diesel locomotive, test object, modernization, modeling.

Рецензент д.т.н., професор Крашенінін О.С. (УкрдУЗТ)

Поступила 11.01.2016 p.

Фалендыш А.П., д.т.н., проф., заведующиий кафедрой «Теплотехника и тепловые двигатели», Украинский государственный университет железнодорожного транспорта, Харьков, Украина.

Hомер ORCID: https://orcid.org/0000-0003-3602-7945

Иванченко Д.А., ассистент кафедры «Эксплуатаџия $u$ ремонт подвижного состава», Украинский государственный университет железнодорожного транспорта, Харьков, Украина.

Номер ORCID: http://orcid.org/0000-0002-3024-3930

Falendysh A., Doctor of Technical Sciences, Professor, Head of Department of Thermotechnics and Heat Engines, Ukrainian State University of Railway Transport, Kharkiv, Ukraine.

Hомер ORCID: https://orcid.org/0000-0003-3602-7945

Ivanchenko D., Assistant of Department "Exploitation and Repair of Rolling Stock", Ukrainian State University of Railway Transport, Kharkiv, Ukraine.

Hомер ORCID: http://orcid.org/0000-0002-3024-3930 